\title{
Papers
}

\section{Application of the principle of marginal analysis to sampling practice using prostatic chippings as a model}

\author{
N E I Langlois, C Donaldson
}

\begin{abstract}
Aims-To demonstrate an application of health economic principles in histopathology by using the sampling of transurethral resections of prostate specimens. By demonstrating how marginal costs are calculated the aim is to illustrate that the potential opportunity cost of sampling entire specimens is much greater than would be anticipated by taking average cost, or the cost of producing a histological section alone.

Method-A mathematical model is used with data obtained from the Aberdeen pathology department files and published estimates of the likely percentage of cancerous chippings in each specimen.

Results-The average cost of each cancer detected remains low, between $£ 47$ and $£ 151$, in all the scenarios examined. However, the marginal costs can become high, exceeding $£ 10000$ in larger specimens, if all the chippings are processed.

Conclusions-This study demonstrates that there are potential opportunity cost penalties to histopathological services associated with sampling strategies. Although the results are derived from a hypothetical mathematical model using local data that applies only to histopathology, the method could be widely applied. The principles of marginal analysis should be performed by multidisciplinary teams and include outcomes as well as a broader range of costs, including those that arise subsequent to diagnosis. (f Clin Pathol 1998;51:104-107)
\end{abstract}

Pathology, University of Aberdeen, Medical School, Foresterhill, Aberdeen AB25 2ZD, UK

N E I Langlois

Health Economics Research Unit, University of Aberdeen C Donaldson

Correspondence to: Dr Langlois.

Accepted for publication 10 October 1997 to maximise benefit to the community by minimising opportunity cost, which requires measurement of both the costs (or resources used) and the benefits produced by various health care options.

This is not as big a task as it may seem, as economists argue that this activity should focus on the comparison of marginal costs and benefits, a process that is referred to as marginal analysis. Marginal cost is the cost of producing one unit more, or less, of a service that is provided, whereas the average cost is the total cost of the service divided by the total number of units produced; these need not be the same as some expenses, such as overheads and staff wages, remain constant and do not change with small variations in workload. In the context of a histopathology service where the budget is limited, marginal analysis may focus on the marginal cost of the number of tissue cassettes used to embed prostatic chippings, endometrial resections, and bladder curettings to determine the most productive manner to handle a mix of these specimens and to minimise opportunity cost.

This study aimed at demonstrating how economic principles may aid decision making about best practice in clinical pathology using a case study of the amount of material that should be examined in transurethral resections of prostate (TURP) specimens.

A study by Golimbu and colleagues in 1981 revealed that only $12 \%$ of pathologists process all material when more than $10 \mathrm{~g}$ is received ${ }^{1}$ and, although this information is dated, the tradition of sampling such specimens is generally upheld. However, such selectiveness may result in an underestimate in the prevalence of malignancy, in particular, stage A 1 disease (less than $5 \%$ of tissue malignant, and not high grade) may be overlooked. Therefore, it has been advocated that in patients 60 years or under the entire specimen should be processed with one section per block examined, as in these subjects stage $\mathrm{A} 1$ disease may progress to become clinically significant. ${ }^{2}$ Nonetheless, such an approach does not take into account opportunity costs, which will be explored below. In essence, the question is whether the extra benefit of such a policy is worth the additional, or marginal, cost incurred. 
Table 1 Marginal analysis for median sized sample (12 g, 60 chippings), assuming 5\% contain cancer

\begin{tabular}{lcclllllr}
\hline $\begin{array}{l}\text { Tissue } \\
\text { casettes }\end{array}$ & $\begin{array}{l}\text { Chips } \\
\text { examined }\end{array}$ & $\begin{array}{l}\text { Percentage } \\
\text { examined }\end{array}$ & $\begin{array}{l}\text { Probability of } \\
\text { cancer }\end{array}$ & $\begin{array}{l}\text { Extra } \\
\text { cancers }\end{array}$ & Total cost & Added cost & Average cost & Marginal cost \\
\hline 1 & 9 & 15 & 0.3914 & 0.3914 & $£ 42.50$ & $£ 42.50$ & $£ 108.57$ & $£ 108.57$ \\
2 & 18 & 30 & 0.6645 & 0.2731 & $£ 45.00$ & $£ 2.50$ & $£ 67.72$ & $£ .15$ \\
3 & 27 & 45 & 0.8406 & 0.1760 & $£ 47.50$ & $£ 2.50$ & $£ 56.51$ & $£ 14.20$ \\
4 & 36 & 60 & 0.9409 & 0.1003 & $£ 50.00$ & $£ 2.50$ & $£ 53.14$ & $£ 24.93$ \\
5 & 45 & 75 & 0.9867 & 0.0459 & $£ 52.50$ & $£ 2.50$ & $£ 53.21$ & $£ 54.53$ \\
6 & 54 & 90 & 0.9994 & 0.0127 & $£ 55.00$ & $£ 2.50$ & $£ 55.03$ & $£ 196.67$ \\
7 & 60 & 100 & 1.0000 & 0.0006 & $£ 57.50$ & $£ 2.50$ & $£ 57.50$ & $£ 4166.66$ \\
\hline
\end{tabular}

\section{Methods}

Reports for TURP specimens were retrieved from the files of the department of pathology, Aberdeen Royal Hospitals from 1 January 1995 until 100 cases had been acquired in which there was a record of the weight of the received specimen. From these data the median weight of sample received was calculated. Specimens without recorded weights were not included as these reflected the working practice of some pathologists rather than a source of potential bias.

An estimate of the weight of chippings that would usually be held by a tissue cassette was obtained by filling 10 cassettes in the normal fashion and dividing the weight of chippings held by them by 10 . One hundred TURP chippings were weighed to estimate the mean weight of one chip.

The probability of detecting cancer in a given tissue cassette is given by the formula below when $\mathrm{r}=0$ :

$$
\mathrm{P}=1-\frac{\left(\begin{array}{c}
\mathrm{R} \\
\mathrm{r}
\end{array}\right) \times\left(\begin{array}{c}
\mathrm{N}-\mathrm{R} \\
\mathrm{n}-\mathrm{r}
\end{array}\right)}{\left(\begin{array}{l}
\mathrm{N} \\
\mathrm{n}
\end{array}\right)}
$$

where $\mathrm{N}$ is total number of objects (prostatic chippings) received in the sample referred for pathological examination; $\mathrm{R}$ is the theoretical number of objects with the characteristic being investigated-that is, number of chippings containing cancer; $\mathrm{n}$ is the number of objects examined-that is, the number of chippings subjected to histological examination; and $\mathrm{r}$ is the actual number with the characteristic observed in the sample.

$\left(\begin{array}{c}\mathrm{R} \\ \mathrm{r}\end{array}\right)=\frac{\mathrm{R} !}{\mathrm{r} !(\mathrm{R}-\mathrm{r}) !}$ that is, combination where $\mathrm{R}$ ! is $\mathrm{R}$ factorial.

For the purpose of this exercise the median sample size of TURP specimen was used to calculate the median number of chips received, and this number of chips was used for $\mathrm{N}$ (the number of objects). The number in the sample (n) was taken as the number of tissue cassettes multiplied by the estimated number of chips that would be held by a tissue cassette. $R$ (theoretical number with characteristic) was allocated a value of the median sample size multiplied by 0.05 to represent the situation when $5 \%$ of the TURP specimen was malignant. This threshold of $5 \%$ of chippings containing cancer was derived from work of Moore and colleagues ${ }^{3}$ who found that the mean percentage of malignant fragments was $6.7 \%$ in specimens that were clinically considered to be benign. For the purpose of the mathematical model it is assumed that examining all chippings would detect $100 \%$ of cancers, but it is acknowledged that this could only occur if specimens were levelled.

An estimate of $£ 2.50$ for the material costs only of producing one haematoxylin and eosin stained histological slide from a tissue cassette was used. An overhead cost of $£ 40.00$ was used, which was derived from NHS Trust information, and it is assumed this remains constant. Table 1 sets out the average cost of each cancer detected as the total cost divided by the probability of detecting cancer for that number of cassettes; whereas the marginal cost was calculated from the added cost of using one extra cassette divided by the extra cancers detected by incurring that added cost.

Sensitivity analysis was performed to examine the costs in different scenarios that might arise by varying the proportion of chippings containing malignancy and the size of the sample.

\section{Results}

The median weight of a TURP specimen was $12.0 \mathrm{~g}$ (range 2-39 g; mean (SD) 13.5 (8.5)), and each tissue cassette held on average $1.8 \mathrm{~g}$ of chippings. One hundred chips weighed $20 \mathrm{~g}$, therefore the mean weight of one chip was

Table 2 Marginal analysis for $24 \mathrm{~g}$ sized sample, assuming 5\% of chips contain cancer

\begin{tabular}{lccccccrr}
\hline $\begin{array}{l}\text { Tissue } \\
\text { cassettes }\end{array}$ & $\begin{array}{l}\text { Chips } \\
\text { examined }\end{array}$ & $\begin{array}{l}\text { Percentage } \\
\text { examined }\end{array}$ & $\begin{array}{l}\text { Probability of } \\
\text { cancer }\end{array}$ & Extra cancers & Total cost & Added cost & Average cost & Marginal cost \\
\hline 1 & 9 & 7.5 & 0.3801257 & 0.3801257 & $£ 42.50$ & $£ 42.50$ & $£ 111.81$ & $£ 111.81$ \\
2 & 18 & 15.0 & 0.6313560 & 0.2512342 & $£ 45.00$ & $£ 2.50$ & $£ 71.27$ & $£ .95$ \\
3 & 27 & 22.5 & 0.7913226 & 0.1599627 & $£ 47.50$ & $£ 2.50$ & $£ 60.03$ & $£ 15.63$ \\
4 & 36 & 30.0 & 0.8887189 & 0.0973963 & $£ 50.00$ & $£ 2.50$ & $£ 56.26$ & $£ 25.67$ \\
5 & 45 & 37.5 & 0.9448744 & 0.0561556 & $£ 52.50$ & $£ 2.50$ & $£ 55.56$ & $£ 44.52$ \\
6 & 54 & 45.0 & 0.9751259 & 0.0302514 & $£ 55.00$ & $£ 2.50$ & $£ 56.40$ & $£ 82.64$ \\
7 & 63 & 52.5 & 0.9900654 & 0.0149340 & $£ 57.50$ & $£ 2.50$ & $£ 58.08$ & $£ 167.34$ \\
8 & 72 & 60.0 & 0.9966405 & 0.0065750 & $£ 60.00$ & $£ 2.50$ & $£ 60.20$ & $£ 380.23$ \\
9 & 81 & 67.5 & 0.9991068 & 0.0024663 & $£ 62.50$ & $£ 2.50$ & $£ 62.56$ & $£ 1013.65$ \\
10 & 90 & 75.0 & 0.9998374 & 0.0007306 & $£ 65.00$ & $£ 2.50$ & $£ 65.01$ & $£ 3421.65$ \\
11 & 99 & 82.5 & 0.9999851 & 0.0001477 & $£ 67.50$ & $£ 2.50$ & $£ 67.50$ & $>£ 10000.00$ \\
12 & 108 & 90.0 & 0.9999997 & 0.0000146 & $£ 70.00$ & $£ 2.50$ & $£ 70.00$ & $>£ 10000.00$ \\
13 & 117 & 92.5 & 1.0000000 & 0.0000003 & $£ 72.50$ & $£ 2.50$ & $£ 72.50$ & $>£ 10000.00$ \\
14 & 120 & 100 & 1.0000000 & 0.0000000 & $£ 75.00$ & $£ 2.50$ & $£ 75.00$ & $>£ 10000.00$ \\
\hline
\end{tabular}


Table 3 Marginal analysis for a $6 \mathrm{~g}$ sized sample, assuming 5\% contain cancer

\begin{tabular}{|c|c|c|c|c|c|c|c|c|}
\hline Tissue casettes & $\begin{array}{l}\text { Chips } \\
\text { examined }\end{array}$ & $\begin{array}{l}\text { Percentage } \\
\text { examined }\end{array}$ & $\begin{array}{l}\text { Probability of } \\
\text { cancer }\end{array}$ & $\begin{array}{l}\text { Extra } \\
\text { cancers }\end{array}$ & Total cost & Added cost & Average cost & Marginal cost \\
\hline \multicolumn{9}{|c|}{ Using four tissue cassettes } \\
\hline 1 & 9 & 30 & 0.5172 & 0.5172 & $£ 42.50$ & $£ 42.50$ & $£ 82.17$ & $£ 82.17$ \\
\hline 2 & 18 & 60 & 0.8428 & 0.3310 & $£ 45.00$ & $£ 2.50$ & $£ 53.05$ & $£ 7.55$ \\
\hline 3 & 27 & 90 & 0.9931 & 0.1448 & $£ 47.50$ & $£ 2.50$ & $£ 47.83$ & $£ 17.26$ \\
\hline 4 & 36 & 100 & 1.0000 & 0.0069 & $£ 50.00$ & $£ 2.50$ & $£ 50.00$ & $£ 362.50$ \\
\hline \multicolumn{9}{|c|}{ Using three tissue cassettes } \\
\hline 1 & 10 & 33 & 0.5632 & 0.5632 & $£ 42.50$ & $£ 42.50$ & $£ 75.46$ & $£ 75.46$ \\
\hline 2 & 20 & 67 & 0.8966 & 0.3333 & $£ 45.00$ & $£ 2.50$ & $£ 50.19$ & $£ 4.50$ \\
\hline 3 & 30 & 100 & 1.0000 & 0.1034 & $£ 47.50$ & $£ 2.50$ & $£ 47.50$ & $£ 24.17$ \\
\hline
\end{tabular}

Table 4 Marginal analysis for median sized sample (12 g, 60 chippings)

\begin{tabular}{|c|c|c|c|c|c|c|c|c|}
\hline $\begin{array}{l}\text { Tissue } \\
\text { cassettes }\end{array}$ & $\begin{array}{l}\text { Chips } \\
\text { examined }\end{array}$ & $\begin{array}{l}\text { Percentage } \\
\text { examined }\end{array}$ & $\begin{array}{l}\text { Probability of } \\
\text { cancer }\end{array}$ & Extra cancers & Total cost & Added cost & Average cost & Marginal cost \\
\hline \multicolumn{9}{|c|}{ Assuming $2.5 \%$ of chips contain cancer } \\
\hline 1 & 9 & 15 & 0.2797 & 0.2797 & $£ 42.50$ & $£ 42.50$ & $£ 151.97$ & $£ 151.97$ \\
\hline 2 & 18 & 30 & 0.5136 & 0.2339 & $£ 45.00$ & $£ 2.50$ & $£ 87.62$ & $£ 10.69$ \\
\hline 3 & 27 & 45 & 0.7017 & 0.1881 & $£ 47.50$ & $£ 2.50$ & $£ 67.69$ & $£ 13.29$ \\
\hline 4 & 36 & 60 & 0.8441 & 0.1424 & $£ 50.00$ & $£ 2.50$ & $£ 59.24$ & $£ 17.56$ \\
\hline 5 & 45 & 75 & 0.9407 & 0.0966 & $£ 52.50$ & $£ 2.50$ & $\{55.81$ & $£ 25.88$ \\
\hline 6 & 54 & 90 & 0.9915 & 0.0508 & $£ 55.00$ & $£ 2.50$ & $£ 55.47$ & $£ 49.17$ \\
\hline 7 & 60 & 100 & 1.0000 & 0.0085 & $£ 57.50$ & $£ 2.50$ & $£ 57.50$ & $£ 295.00$ \\
\hline \multicolumn{9}{|c|}{ Assuming $10 \%$ of chips contain cancer } \\
\hline 1 & 9 & 15 & 0.64027025 & 0.6402703 & $£ 42.50$ & $£ 42.50$ & $£ 66.38$ & $£ 66.38$ \\
\hline 2 & 18 & 30 & 0.89521811 & 0.2549479 & $£ 45.00$ & $£ 2.50$ & $£ 50.27$ & $£ 9.81$ \\
\hline 3 & 27 & 45 & 0.97787690 & 0.0826588 & $£ 47.50$ & $£ 2.50$ & $£ 48.57$ & $£ 30.24$ \\
\hline 4 & 36 & 60 & 0.99731151 & 0.0194346 & $£ 50.00$ & $£ 2.50$ & $£ 50.13$ & $£ 128.64$ \\
\hline 5 & 45 & 75 & 0.99990003 & 0.0025885 & $£ 52.50$ & $£ 2.50$ & $£ 52.51$ & $£ 965.80$ \\
\hline 6 & 54 & 90 & 0.99999998 & 0.0000998 & $£ 55.00$ & $£ 2.50$ & $£ 55.00$ & $>£ 10000.00$ \\
\hline 7 & 60 & 100 & 1.00000000 & 0.0000002 & $£ 57.50$ & $\hat{£} 2.50$ & $£ 57.50$ & $>\hat{£} 10000.00$ \\
\hline
\end{tabular}

$0.2 \mathrm{~g}$. Thus, for a typical specimen, 60 chips would be received and nine would be placed in each tissue cassette.

From the above data, the percentage of tissue that would be sampled by a given number of blocks could be calculated, together with the probability of detecting cancer if it was present (table 1). There was a higher average cost associated with the first cassette, which represents the "penalty" of making the commitment to process, rather than to discard, the sample. Thereafter, the average cost of each cancer detected remained more or less constant, even when the whole sample was processed. However, the marginal cost (the extra cost for each extra case detected) increased dramatically. It appeared there was a cost penalty in processing more than five tissue cassettes of chips.

The sensitivity of these results was tested by assuming sample sizes of $24 \mathrm{~g}$ or $6 \mathrm{~g}$. Tables 2 and 3 show that for these sample sizes the average cost of each cancer detected for using a cassette to embed the last remaining chips stayed low. However, the marginal costs were greater when the whole specimen was processed. For the larger specimen $(24 \mathrm{~g})$ a considerable increase in the marginal cost occurred after the seventh tissue cassette was used, and the marginal cost for processing the complete sample was extremely high. In the case of the $6 \mathrm{~g}$ sample, an alternative scenario was considered (table 3 ) in which extra tissue is placed in the first three cassettes enabling all the chippings to be examined in three cassettes. If this practice was adopted the marginal cost for examining all the tissue remained low.

In table 4 the assumed fraction of chips that contained cancer was set at $2.5 \%$ and $10 \%$. The percentage of chippings containing malig- nancy had a dramatic effect on the marginal costs. In samples with $2.5 \%$ cancerous material, the marginal costs remained low until the last cassette was used, but if $10 \%$ of chips contained carcinoma the marginal costs became high if more than four tissue cassettes were used.

\section{Discussion}

Despite the introduction of the concept of resource management (making the most efficient use of resources available) by the NHS white paper "Working for patients", and the National Audit Commission's advocation of a "value for money" approach to pathology, ${ }^{4}$ the discipline appears to have been largely untouched by such recommendations. Various costing systems for laboratory work have been proposed, but such costing strategies have been directed mainly at permitting comparison between laboratories or providing information to purchasers. ${ }^{5}$ In terms of economic analysis, cost-effectiveness has been examined in routine postmortem histology. ${ }^{6}$ For a discipline where there is good scope for marginal cost analysis, such studies are scarce. One area in which marginal analysis appears to be suited is in the issue of sampling, as examined in this study.

It has been claimed that small volumes of high grade tumour may be missed by sampling ${ }^{3}$ and complete sampling undoubtedly increases the detection rate of cancer in TURP specimens. ${ }^{8}$ Selection of chips for processing would ideally be performed macroscopically but this has been shown not to be reliable. ${ }^{1}$ With respect to how much to select for examination, some cost analysis was performed by Vollmer, who concluded that examining five 
cassettes of tissue would be sufficient to diagnose most cases and, while examining all tissue from TURP specimens would detect all cancers, the additional cost for each patient diagnosed would be US $\$ 4000$ (in 1986). ${ }^{8}$ However, others have asserted that nearly all the material must be examined to detect even $90 \%$ of all cancers if there are a small number of malignant chippings. ${ }^{3}$

The analysis produced here (table 1 ) shows the cost analysis in terms of average and marginal costs. There is a cost penalty incurred in taking the decision to process the specimen, which is displayed in the cost of the first cassette; thereafter, the average cost of detecting adenocarcinoma of the prostate remains relatively low and constant. However, the marginal costs exhibit a different pattern, as the likelihood of a further tissue cassette disclosing a tumour that was not encountered in any previous cassette falls the marginal cost rises. The price of using the seventh tissue cassette to embed all the chippings in terms of cost for each tumour found is extremely high. This situation is analogous to that seen in the proposed stool guaiac test for large bowel carcinoma. ${ }^{9}$ Examining marginal costs may aid the decision of how much to sample of a range of specimens if the number of tissue cassettes that can be processed in a financial year is limited-for instance, determining the number of tissue blocks to take from an omentectomy specimen obtained from a staging operation for ovarian cancer. With reference to the concept of opportunity cost, it could be argued that the resources employed in analysing seven cassettes of prostatic chippings instead of six could be more productively used in some other activity - for example, embedding all tissue and cutting extra levels on skin biopsy specimens containing melanoma.

The sensitivity analysis indicates that the marginal costs are influenced by the proportion of chippings containing carcinoma and the size of the specimen. However, the aim of the analysis was to demonstrate that there is a marginal cost that accompanies sampling and that the size of such marginal costs may not be apparent until formally calculated. Thus the decision to examine the whole of a TURP specimen may have far greater opportunity costs than the perceived $£ 2.50$ for producing an extra histological section. Table 3 indicates that in the case of smaller samples, embedding the entire specimen could be justified, but only if this is achieved by limiting the number of cassettes used, and not by employing a fourth cassette to hold the last of the chips. This pro- vides another example of how marginal analysis could influence practice. However, it must be considered that overloading tissue cassettes may prevent sectioning of the maximum area of each chipping. In the case of larger samples $(24 \mathrm{~g})$, the rising marginal costs are elegantly demonstrated (table 2), and the marginal costs incurred by examining more than seven tissue cassettes rise dramatically.

It is accepted that this is a simplified study using local figures that do not take into account variations either within or between laboratories-for example, the amount of tissue placed in each cassette. Furthermore, the model presented is hypothetical and has not been tested in a practical setting. Examining cost and thinking in terms of marginal analysis could result in a more optimal use of health service resources in that it may be possible to determine the point where the gain in benefit from provding additional resources to one area exceeds the loss as a consequence of decreasing funding of another activity.

Finally, it has to be recognised that there are two caveats to the analysis presented. First, cases of cancer detected is a narrow measure of outcome. Such a measure should take into account clinical outcomes associated with any treatment or further testing subsequent to diagnosis. Second, costs associated with treatment and testing should also be included. However, it is hoped that even the limited analysis presented here demonstrates the importance of health economic principles that may be applied by multidisciplinary teams of researchers and practitioners.

The authors thank Andrew Kennedy of the Health Services Research Unit of the University of Aberdeen for providing the formula for calculating the probability of detecting cancer and Dr J G Simpson for his critical reading of the manuscript. The Health Economics Research Unit is supported by the Chief Scientist Office of the Scottish Office Department of Health (SODoH); however, the views expressed in this paper are those (SODoH); however, the views

1 Golimbu M, Glasser J, Schinella R, et al. Stage A prostate colimbu $M$, Glasser $\mathrm{J}$, Schinella $\mathrm{R}$, et al. Stage A prostate
Urology cancer from

2 Harnden P, Parkinson MC. Macroscopic examination of prostatic specimens. F Clin Pathol 1995;48:693-700.

3 Moore GH, Lawshe B, Murphy J. Diagnosis of adenocarcinoma in transurethral resectates of the prostate gland. $A m$ f Surg Pathol 1986;10:165-9.

4 Audit Commission. The pathology services: a management review. London: HMSO, 1991.

5 Gozzard DI, Macaulay ME, Nuttall DS, et al. A pragmatist's approach to pathology costing: the Welsh datatree project. 7 Clin Pathol 1992;45:650-3.

6 Reid WA. Cost effectiveness of routine histopathology. $\mathcal{F}$ Clin Pathol 1987;40:459-61.

7 Chan KW. Cost effectiveness of routine necropsy renal histology [letter]. F Clin Pathol 1988;41:233.

8 Vollmer RT. Prostate cancer and chip specimens: complete versus partial sampling. Hum Pathol 1986;17:285-90.

9 Neuhauser D, Lewicki AM. What do we gain from the sixth stool guaiac? N Engl f Med 1975; 293:226-8 